\title{
Polyaniline Composite Membranes Synthesis in Presence of Various Acid Dopants for Pressure Filtration
}

\author{
(Sintesis Membran Komposit Polyanilin dengan Kehadiran Pelbagai Jenis Asid Dopan untuk Penurasan Tekanan) \\ Rosiah Rohani*, Izzati Izni Yusoff, Farah Adlyna Mey Efdi \& Mohd Usman Mohd Junaidi \\ Faculty of Engineering \& Built Environment, Universiti Kebangsaan Malaysia, Malaysia \\ Asif Ali Qaiser \\ University of Engineering \& Technology, Pakistan
}

\begin{abstract}
Polyaniline is a conductive polymer that is recently used as a material in producing a pressure filtration membrane. Polyaniline can be doped in various acids as dopants of different sizes and shapes to modify its inherent properties to produce membrane with high flux and rejection. This work is aimed to fabricate polyaniline composite membrane in presence of different acids as dopants namely hydrochloric acid, maleic acid, poly(methyl vinylether) acid (PMVEA) and polyacrylic acid (PAA). This polyaniline was coated onto microporous polyvinylidene fluoride (PVDF) support by using a specially fabricated two compartment cell. The field emission scanning electron microscope (FESEM) results show that the morphology of the coated polyaniline on PVDF membrane support is in globular shapes, which elongates at different sizes depending to the acid used. From the thermal analysis, the melting point of polyaniline coated PVDF membrane remains at $260^{\circ} \mathrm{C}$, similar as obtained in the pristine microporous PVDF indicating no thermal change upon polyaniline coating. From all membranes prepared, the doped polyaniline membrane possessed a good conductivity value except for polyaniline-PMVEA membrane, which has the lowest value. In terms of the membrane filtration performance, which was measured based on the flux of pure water and polyethylene glycol (PEG) rejection, polyaniline-PMVEA membrane has a high flux and the highest PEG rejection. This result indicates that the conductivity does not influence much on the membrane filtration performance, but rather due to the physical coating itself. Different acid dopants present during polyaniline coating will lead to different filtration performance.
\end{abstract}

Keywords: Polyaniline; Composite membrane; Chemical polymerization; Acid dopant; Pressure filtration

\section{INTRODUCTION}

Membrane technology has recently evolved in many industries by implying the recovery and reuse or sale of previously wasted materials. This practice enables these industries to be more environmental friendly by decreasing the amount of waste and become more cost-effective, as some high-value materials can be recovered from the waste stream. The water and wastewater treatment industry is one of the main industries that dependent on membrane technology as one of the treatment and recovery technology. However, commercially used membranes such as polysulfone (PSf) have limitations where they have fixed separation selectivity. This requires development of new membrane to allow changeable separation selectivity. Additionally, effective removal of uncharged contaminants from wastewater is problematic using low pressure membrane operation, which required additional chemical treatment steps. Thus, the introduction of conducting polymer $(\mathrm{CP})$ in the manufacturing of a pressure filtration membrane is attractive due to its high electrical conductivity and mechanical flexibility, which is very promising to overcome commercial membrane problems.

CP such as polyaniline has been extensively investigated to elucidate their intrinsic transport properties owing to their low dimensionality, light weight, biological compatibility for ease of cost and manufacturing. In future, membrane fabricated from $\mathrm{CP}$ material could improve the complex molecular separations that enable by existing selective polymer membrane. Besides having desirable properties, $\mathrm{CP}$ can be tuned with various electrolytes to influence the membrane free volume, which controls permeance diffusivity. Hence, the selectivity can be controlled by manipulating the electrical conductivity on the membrane. According to Sairam et al. , they have introduced and investigated polyaniline as a potential $\mathrm{CP}$, used to fabricate a pressure filtration membrane. Polyaniline is of interest as it can easily form free-standing film and it can be used in various applications such as fuel cells, batteries, and sensors. Moreover, unique characteristics and low manufacturing cost of polyaniline are the main reasons to develop polyaniline based membranes.

Previously, there are several methods that can be applied in polyaniline membranes fabrication including non-solvent induced phase separation, flash welding and polymer blending to increase its conductivity and hydrophilicity. According to Mansouri et al. polyaniline membrane fabricated with high electrical conductivity and great hydrophilicity properties tend to have better resistance towards organic and biological fouling. Another potential approach in polyaniline fabrication applied in the 
recent works is by using electrochemical polymerization to promote the development of polyaniline coating composite membranes with higher electrical conductivity and improved mechanical properties. However, free standing polyaniline in the form of continuous flat membrane is relatively less durable than the present commercial membranes. Therefore, polyaniline composite membranes were prepared to improve its mechanical strength and filtration performance.

Various strategies have been explored by controlling the parameters involved during the chemical polymerization of polyaniline such as different acid dopants used, polymerization temperatures times, etc. The presence of acid dopant has found to influence the CP in terms of polymer structure and the polymerization reaction rate. Desilvestro et al. observed that polymerization rate of polyaniline from acidic solutions was influenced by the acid dopant in which it was fabricated with the polymerization reaction has occurred faster in sulfuric acid $\left(\mathrm{H}_{2} \mathrm{SO}_{4}\right)$ solution than in $\mathrm{HCl}$. The polymerization rate has also influenced the morphologicak properties of the synthesized polyaniline membranes. Polyaniline fabricated by Desilvestro et al. using $\mathrm{HCl}$ dopant was found to be in a fibrils packed network with diameters of 0.2-0.3 $\mu \mathrm{m}$. Meanwhile, polyaniline membrane polymerized in $\mathrm{H}_{2} \mathrm{SO}_{4}$ dopant appeared in short fibrous stumps with typically length less than $0.5 \mu \mathrm{m}$. This shows that different acid dopants presence during polymerization may results in different polyaniline membrane microstructures.

Therefore, the aim of this work is to fabricate pressure filtration membranes from polyaniline by coating it onto microporous polyvinylidene fluoride (PVDF) as the membrane support in presence of various acid dopants. The chemical polymerization of polyaniline from aniline and ammonium persulfate (APS) was conducted in a specially fabricated twocompartment cell where the aniline and APS acidic solution were filled in each compartment that was separated by the microporous PVDF in between them. Apart from different types of acid dopant effect, the effects of polymerization times during chemical polymerization were also investigated. The synthesized membranes were characterized by using Fourier Transform Infrared (FTIR) spectroscopy for their chemical properties, thermal properties by differential scanning calorimetry (DSC) while surface morphology of the membranes was analysed via field emission scanning electron microscopy (FESEM). The membrane electrical conductivity was measured by Inductance, Capacitance and Resistance meter (LCR meter) and the filtration performance of the membranes were tested via flux and rejection of Polyethylene glycol (PEG) at different molecular weights (MW) through the membranes in a dead-end filtration unit.

\section{MATERIALS AND METHODS}

\section{MATERIALS}

The microporous polyvinylidene fluoride (PVDF) support of $0.01 \mu \mathrm{m}$ porosity was purchased from Hangzhou ANOW Microfiltration Co. Ltd., China. Aniline monomer, ammonium persulfate (APS), poly(methyl vinyl ether-alt-maleic acid) (PMVEA) (MW 216,000 g/mol) and maleic acid (MA) (MW $116.07 \mathrm{~g} / \mathrm{mol}$ ) were purchased from Sigma-Aldrich Chemical, USA. All these chemicals including Polyacrylic acid (PAA) (MW $651.94 \mathrm{~g} / \mathrm{mol}$, Alfa Aesar, USA) and hydrochloric acid $(\mathrm{HCl})$ (Merck) were used as received.

PREPARATION OF POLYANILINE COMPOSITE MEMBRANES

Polyaniline membranes were synthesized onto microporous PVDF supports in presence of various acid dopants to enhance the performance of the membranes for application in a pressure filtration unit especially in the ultrafiltration (UF) and nanofiltration (NF) ranges. The polymerization of polyaniline was performed by chemical polymerization reaction via diffusion cell technique in a specially fabricated twocompartment cell. Subsequently, the PVDF was sandwiched between the solution of aniline and APS aqueous solutions at two different compartments in the cell. The schematic diagram of the two-compartment cell is presented in Figure 1. The PVDF support was tightly clamped in between the two-compartment loaded with the acidic solutions of aniline on one side and APS on the other side, respectively, in a way to enhance the polymerization of polyaniline onto the support and into the microstructure. Initially, $0.8 \mathrm{~mol} . \mathrm{L}^{-1}$ aniline and $4 \mathrm{wt} . \%$ of acid dopant (PMVEA, MA, $\mathrm{HCl}$ or PAA) were dissolved in $1 \mathrm{M}$ of $\mathrm{HCl}$. Meanwhile, the molar ratio of APS to aniline in the final APS aqueous solutions was set at 1: 1.25 . The stirring speed was maintained at $250 \mathrm{rpm}$ and a stainless steel ring clamp was used to tighten the cell. During the polymerization period, aniline and APS solutions were allowed to counter-diffuse, simultaneously, through the support. After polymerization reaction was completed at varied reaction times $(4,6,8$ hours), the polyaniline coated PVDF membrane was removed from the cell, cleaned with ultrapure water several times and further soaked in $1 \mathrm{M} \mathrm{HCl}$ for 24 hours to achieve a complete protonation and doping of polyaniline in the membranes.

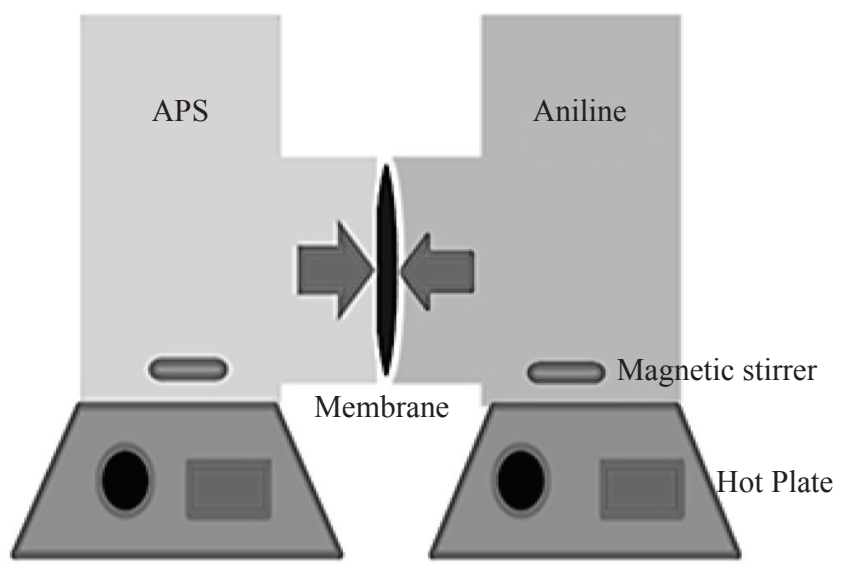

FIGURE 1. Schematic diagram of the two-compartment cell for chemical polymerization of polyaniline onto microporous PVDF support 
MEMBRANE CHARACTERIZATION

Polyaniline deposition percentage (\%) on the PVDF support were measured by gravimetric method. The PANI \% was calculated by measuring the weight difference between the polyaniline coated PVDF membranes and the pristine PVDF support (refer Equation (1)):

$$
\begin{aligned}
& \begin{array}{l}
\text { Polyaniline deposition } \\
\text { percentage }(\%)
\end{array}=\frac{W_{f}-W_{i}}{W_{f}} \times 100 \\
& \text { P }
\end{aligned}
$$

$\mathrm{W}_{\mathrm{i}}$ is the initial weight of pristine PVDF support and $\mathrm{W}_{\mathrm{f}}$ represents the final weight of the polyaniline coated PVDF membrane.

For the determination of the membrane chemical properties, FTIR (ATR) of Thermo Scientific, Nicolet 6700 at a resolution of $4 \mathrm{~cm}^{-1}$ using pressed potassium bromide $(\mathrm{KBr})$ pellets in a transmittance mode was used to record the FTIR spectra of the polyaniline membranes synthesized in different acid dopants. A wavenumber between 4000-600 $\mathrm{cm}^{-1}$ was scanned for 16 times in 1 minute. Meanwhile, the membrane thermal properties were determined via DSC under an inert static flowing of nitrogen gas. The temperature was increased at a rate of $20^{\circ} \mathrm{C} \mathrm{min}-1$ with temperature range between $30-500^{\circ} \mathrm{C}$.

LCR meter (Instek LCR-819) was used to investigate the conducting properties of the fabricated membranes which were prepared in various acid dopants by measuring the membrane resistance after polyaniline polymerization onto the support. The membrane was cut in $1 \times 2 \mathrm{~cm}^{2}$ dimension and attached to the clip to obtain the lead Kelvin resistance value. The average value was calculated based on five (5) readings of resistance values. Equation (2) was used to

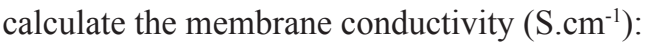

$$
\text { Conductivity }=\frac{D}{L T R}
$$

D represents the distance between two clips, L signifies the length of the cut membrane sample, $T$ resembles the membrane thickness and $\mathrm{R}$ symbolizes the resistance value obtained from the LCR meter.

FESEM of Gemini, SUPRA 55VP-ZEISS equipped with an Energy Dispersive X-ray Analysis (EDX) system where this system was used to observe the surface and cross sectional morphology of the polyaniline coated PVDF membrane doped in different acid dopants. During the sample preparation, the membrane sample was dried, cut and mounted onto a metal stud. It was then gold sputtered. Finally, the prepared sample was being observed under the FESEM at $3 \mathrm{kV}$ and 10 $\mathrm{kV}$ accelerating voltage.

Dead-end filtration unit was setup using a Sterlitech HP4750 Stirred Cell as in Figure 2 to investigate the water flux and the rejection of the synthesized membranes with an effective membrane surface area of $14.6 \mathrm{~cm}^{2}$. Equation (3) was used to calculate the flux at the operating pressure of 3 bar.

$$
\text { Flux, } J=\frac{V}{A}
$$

$\mathrm{J}$ refers to the flux $\left(\mathrm{L} \cdot \mathrm{m}^{-2} \cdot \mathrm{h}^{-1}\right), \mathrm{V}$ is volume of permeate (L), $A$ is effective membrane area $\left(\mathrm{m}^{2}\right)$ and $t$ is operating period (h).

Molecular weight cut-off (MWCO) value was obtained from the PEG rejection profile of the polyaniline coated membranes from $90 \%$. Solute rejection (SR) of the polyaniline coated membranes were evaluated with various MW of PEG solutions from 600 g.mol ${ }^{-1}$ to 20000 g.mol ${ }^{-1}$ with PEG solution concentration of $150 \mathrm{ppm}$ at 3 bar operating pressure. The SR was calculated using Equation (4):

$$
\operatorname{SR}(\%)\left|1 \frac{C_{p}}{C_{f}}\right| \times 100
$$

where, $\mathrm{C}_{\mathrm{f}}$ and $\mathrm{C}_{\mathrm{p}}$ are the PEG concentrations in the feed solution and permeate solution, respectively. The concentration of PEG was determined based on their absorbency in the UVspectrophotometer at a wavelength of $535 \mathrm{~nm}$.

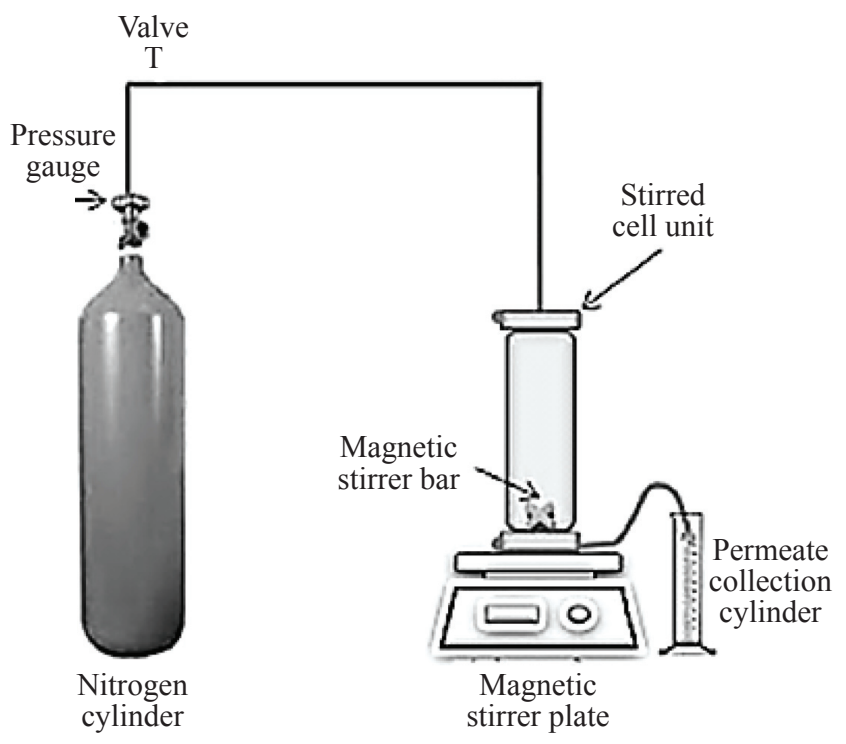

FIGURE 2. Schematic diagram of the dead-end filtration unit

\section{RESULTS AND DISCUSSION}

POLYANILINE DEPOSITION PERCENTAGE

Polyaniline deposition amount on the PVDF membrane support was measured by gravimetry. Results showed that longer reaction time resulted in higher polyaniline deposition to form a layer of polyaniline membrane on the surface of PVDF membrane support. The polymerization reaction time was varied from 4 to $8 \mathrm{~h}$. The highest polyaniline coating of $66.67 \%$ obtained from polyaniline-PAA membrane using dopant PAA at $8 \mathrm{~h}$. Meanwhile, the lowest polyaniline deposition of $25.64 \%$ gained from polyaniline$\mathrm{HCl}$ membrane using $\mathrm{HCl}$ dopant, at $8 \mathrm{~h}$ reaction time. In particular, polyaniline was assumed to be deposited inside 
the pores and on the surface of the PVDF membrane during the polymerization period in the two-compartment cell. Polyaniline has formed in bulk membrane by the counterdiffusion of aniline and APS oxidant through the PVDF support. During the polymerization process, polyaniline deposition was initiated on the aniline-facing side of the membrane and maintained its asymmetric growth in the bulk membrane throughout the polymerization. Based on the results showed in Figure 3 prior to the polymerization reaction time of $8 \mathrm{~h}$, polyaniline intercalation in acid dopant can be arranged in ascending order from $\mathrm{HCl}>\mathrm{MA}>$ PMVEA $>$ PAA.

It was believed that a long polymerization time (several hours) could lead to the development of polymers with higher molecular weight, which would eventually evolve into more flexible molecules through lots of intramolecular chain folding and intermolecular entanglements. Jelmy et al. mentioned the polymerization time to obtain membrane with a good electrical conductivity required a polymerization time of 20-24 h. Polymerization in a specific polymerization techniques emerged as another influence factors. For the composite membranes synthesized by the two-compartmentcell polymerization, impedance decreased about four orders of magnitude from $3 \mathrm{~h}$ to $6 \mathrm{~h}$ polymerization, whereas it decreases to one-half of its value from $6 \mathrm{~h}$ to $30 \mathrm{~h}$ polymerization. This indicates a possible "saturation" intercalation at about $6 \mathrm{~h}$ of polymerization. Therefore, membrane that was polymerized at $8 \mathrm{~h}$ is considered as the best membrane based on the highest amount of polyaniline deposition compared to 4 and $6 \mathrm{~h}$ polymerization. These set of membranes were then analysed for their chemical, electrical, morphological and filtration properties.

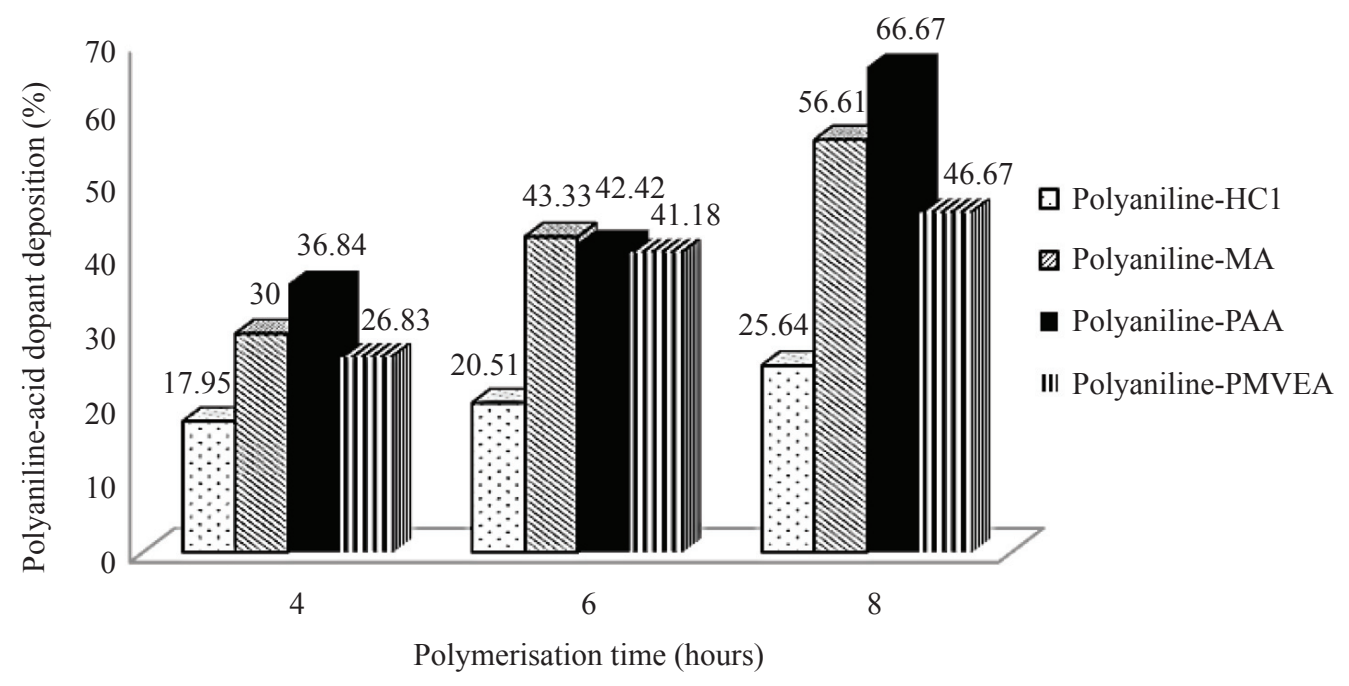

FIGURE 3. The amount of polyaniline-acid dopant deposition percentage (\%) onto PVDF membrane

\section{CHEMICAL ANALYSIS}

Figure 4 shows the FTIR spectra of all fabricated polyaniline composite membranes in comparison to the pure PVDF. Doped polyaniline can be identified by the main peaks at 1588 and $1584 \mathrm{~cm}^{-1}$, corresponding to the $\mathrm{C}=\mathrm{C}$ stretching deformation of quinoid and benzenoid rings, respectively. The $1259.7 \mathrm{~cm}^{-1}$ band is assigned to the C-N stretching of the secondary aromatic amine. The peak at $796.1 \mathrm{~cm}^{-1}$ is assigned to an out-of-plane deformation of $\mathrm{C}-\mathrm{H}$ in the 1,4disubstituted benzene ring. A peak at $1291.9 \mathrm{~cm}^{-1}$, ascribed to the $\mathrm{C}-\mathrm{N}^{+}$stretching vibration in the polar structure, is also observed, indicating that the polyaniline is in a doped state. FTIR was used to investigate the functional group present in the synthesised composite polyaniline doped with different acids. Most of the sharp peaks for all the acids were observed at range of 1600 to $650 \mathrm{~cm}^{-1}$. The highest peak observed is at wavenumber ranges from 1300 to $1100 \mathrm{~cm}^{-1}$ as there are presence of carbonyl or sulfonyl group. For $\mathrm{HCl}$ and PMVEA, quinoid unit (N-Q-N) is shown in vibration bands at 1580.27 and $1580.34 \mathrm{~cm}^{-1}$. Whereas, vibration bands at 1401.50 and
$1491.24 \mathrm{~cm}^{-1}$ indicates benzene ring. Meanwhile, bands at 1274.59 and $1273.97 \mathrm{~cm}^{-1}$ for MA and PAA samples are due to the presence of $\mathrm{C}-\mathrm{N}$ bond, which indicates protonation. From the FTIR spectra, it is confirmed that various acid dopants was incorporated into the polyaniline structure and present on the composite membrane, based on the chemical bonds observed from it.

\section{THERMAL ANALYSIS}

Figure 5 shows the melting temperatures of polyaniline composites membranes on PVDF microporous support at different acid dopant content. The DSC curve peaks indicates the endothermic processes, where energy is required to break the bonds in the successive elimination of $\mathrm{H}_{2} \mathrm{O}, \mathrm{CO}$ and $\mathrm{CO}_{2}$. The first occurring peaks around 100 to $150^{\circ} \mathrm{C}$ signified the removal of moisture and residual organic solvent in the membrane. The second peaks represented endothermic process of the doping acid loss, instead of a glass transition. All of the acids showed a prominent endothermic peak 


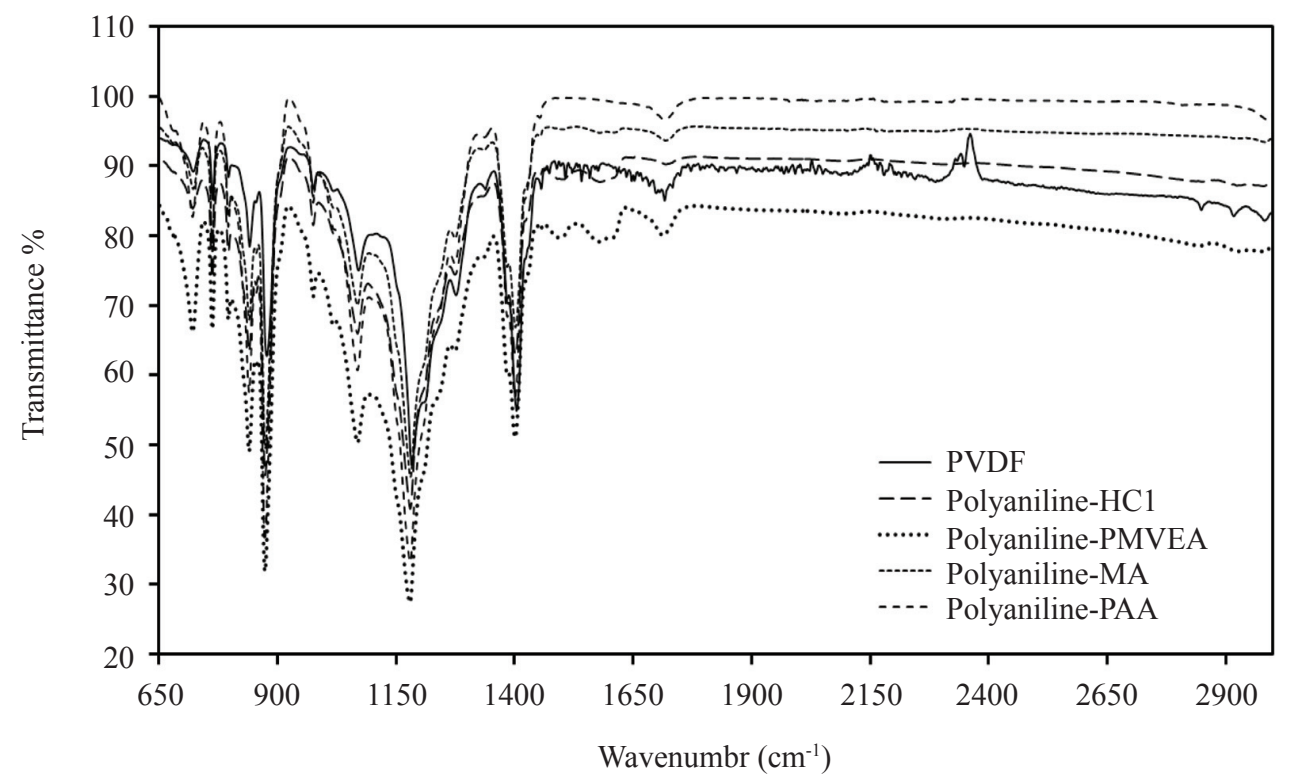

FIGURE 4. FTIR spectra for polyaniline-acid dopant composite membranes in comparison to the pure PVDF

at $260^{\circ} \mathrm{C}$ and an exothermic transition at around $470^{\circ} \mathrm{C}$ which improves the heat resistance and melting point of the composite polyaniline. Pure polyaniline gives a broad endothermic peak at around $110^{\circ} \mathrm{C}$ and exothermic transition at around $270^{\circ} \mathrm{C}$. PAA shows the sharpest endothermic peak and broad exothermic transition. The endothermic peak shows the evolution of water in moisture is absorbed by the polymer. The prominent peak at $260^{\circ} \mathrm{C}$ for all membrane and the PVDF support indicated no thermal change upon polyaniline coating onto the PVDF support, which shows that a thermally stable membrane was obtained from the coating composite technique.

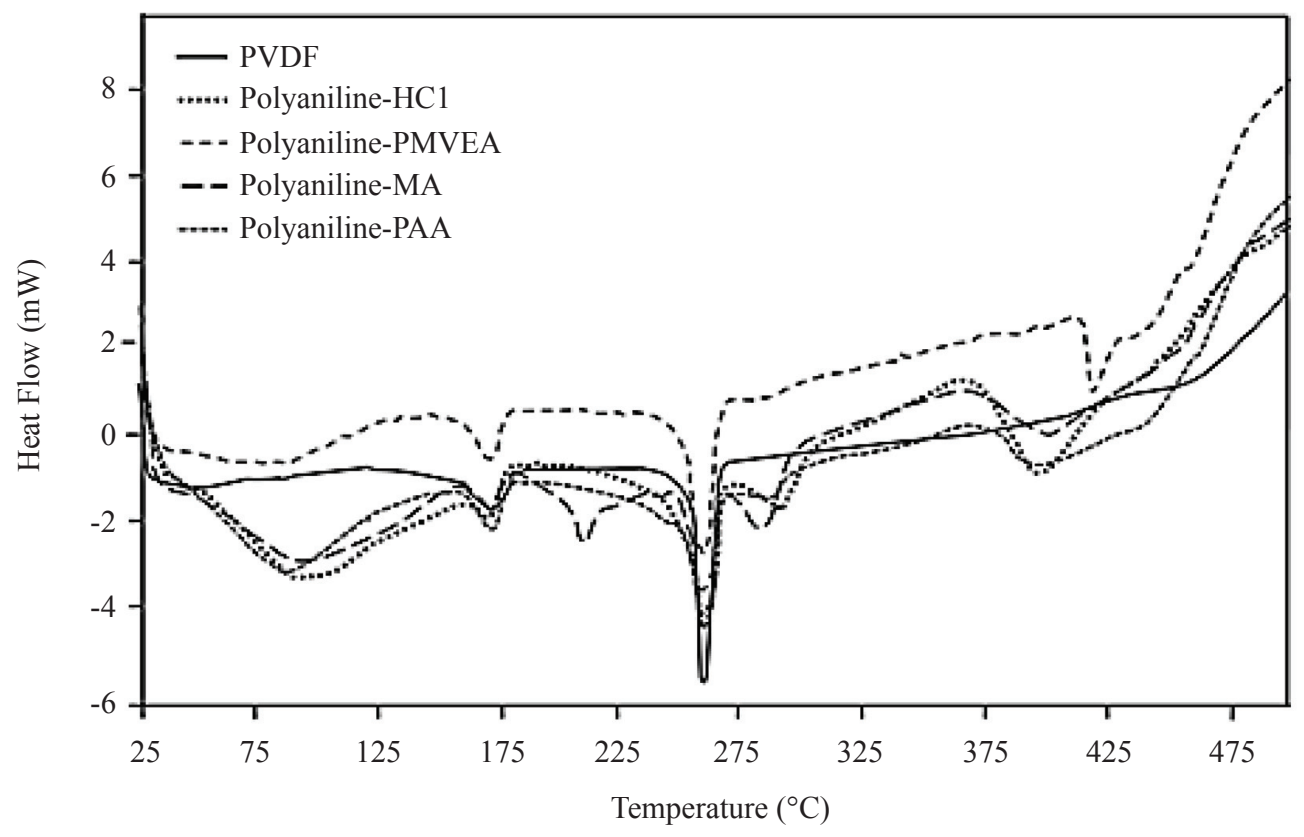

FIGURE 5. DSC thermograms for polyaniline composite membranes doped in different acid dopant in comparison to the pure PVDF

\section{CONDUCTIVITY ANALYSIS}

There are several acid dopants that have been used in the polymerization process and different acid dopant gives different effect to the polymerization. The most preferred method of the synthesis is to use either hydrochloric acid
$(\mathrm{HCl})$ or sulphuric acid $\left(\mathrm{H}_{2} \mathrm{SO}_{4}\right)$ with APS as the oxidant. The presence of $\mathrm{HCl}$ in the polymerization mixture not just resulted in straighter nanorods of the obtained polymers but also shorten the induction time of initiation step of polymerization and also improve their conductivity. As 
tabulated in Table 1, PANI membrane composite doped with different acids has different conductivity value. Membrane doped in MA showed the higher value of electrical conductivity, followed by polyaniline- $\mathrm{HCl}$, polyaniline-PAA. On the other hand, Polyaniline-PMVEA have shown a very low conductivity compared to the other membranes, This was probably due to the fact that PMVEA is a polymeric acid dopant which similar to PAA. PMVEA possesses the biggest molecular weight; thus might cause less polyaniline to form on the PVDF support due to the presence of PMVEA in the polymerization solution. This reduces the number of doping site on the polyaniline itself and thus reducing the conductivity. Bigger MW of PMVEA is believed to create bigger pore structure in the polyaniline composite membrane formation and it has been discussed further in the morphological analysis and filtration performance study.

TABLE 1. Conductivity values of polyaniline composite membranes doped in different acid dopant

\begin{tabular}{cc}
\hline Membrane & Conductivity $(\mathrm{S} / \mathrm{cm})$ \\
\hline Polyaniline-HCl & 0.164 \\
Polyaniline-PMVEA & $6 \times 10^{-6}$ \\
Polyaniline-MA & 0.227 \\
Polyaniline-PAA & 0.061 \\
\hline
\end{tabular}

FESEM ANALYSIS

The electrical conductivity of a polyaniline membrane represents a function of inter-chain and intra-chain electron transfer in polyaniline. This chain electron transfer on the membranes structure is found to influence the morphological properties of the membranes where there are two distinct morphologies observed in FESEM (refer Figure 6). Firstly, polyaniline-MA, polyaniline- $\mathrm{HCl}$ and polyaniline-PAA membrane samples, which have high electrical conductivity, displayed a highly connected coral-like morphology that allows good inter- and intra-chain electron transfer within polyaniline. Meanwhile, polyaniline-PMVEA membrane with the lowest conductivity displayed a loose flake-like morphology with poor connectivity between polyaniline particles. According to Jelmy et al. polyaniline samples with low conductivity showed poor inter-chain polymer morphology, which resulted to poor electron transfer. In overall FESEM observation, all synthesized polyaniline composites demonstrated globular and fingerlike shape structures of different sizes. Sapurina \& Shishov presented similar observation when polyaniline is in contact with acidic material. However, if the $\mathrm{pH}$ of the reaction decreases, granular precipitate would form. For polyaniline- $\mathrm{HCl}$ (Figure 6b) and polyaniline-PMVEA samples (Figure 6c), a globular fragment is easier to distinguish compared to polyaniline-

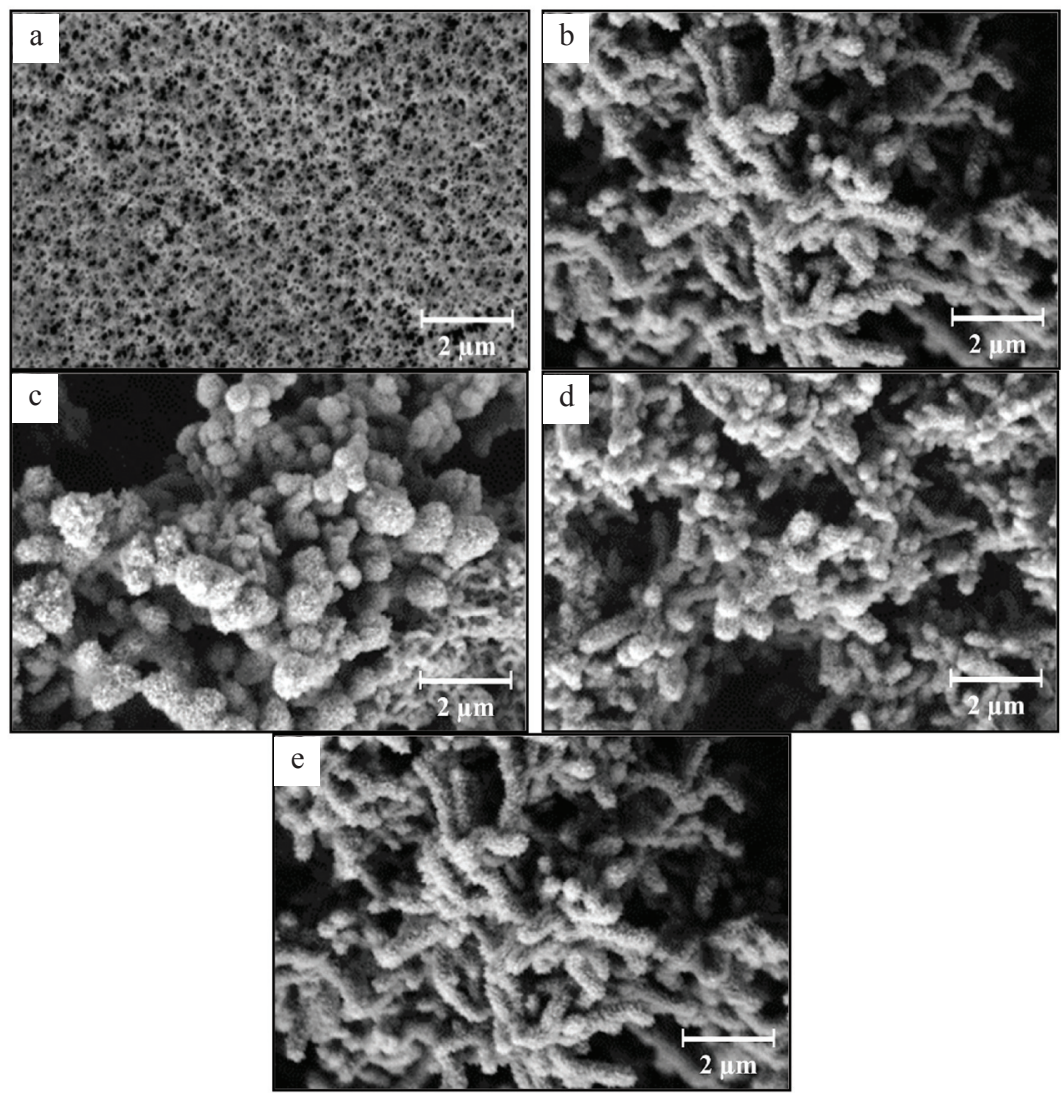

FIGURE 6. FESEM surface images obtained for 8 hours polymerization under magnification 10.00kx for a) Pure PVDF,

b) Polyaniline-HCl, c) Polyaniline-PMVEA, d) Polyaniline-MA and e) Polyaniline-PAA 
MA (Figure 6d) and polyaniline-PAA samples (Figure 6e), where a more protruding fingerlike structure is observed. This indicates that different types of acids give different formation of nanostructures. Though the polyaniline-PMVEA membrane has a bit different structure, polyaniline-PMVEA coating is seemed to completely cover the PVDF surface than the other membranes. Complete coating is more important in determining the membrane filtration properties than other properties investigated.

\section{FILTRATION PERFORMANCE}

The permeation performances of all synthesized membranes were investigated by the water flux and the PEG rejection.
Figure 7 shows the variation of water flux with pressure while Figure 8 shows the PEG rejection profile for membrane doped in different acid dopant performed at different pressure. Figure 7 shows that polyaniline-PAA membrane, which has the highest polyaniline deposition (67\% from Figure 3 ) has the lowest water flux followed by polyaniline-MA (57\%), polyaniline-PMVEA (47\%) and polyaniline- $\mathrm{HCl}(26 \%)$. This result is consistent where the more polyaniline is deposited, the lower water flux is observed. Low water flux could be due to a better coating of polyaniline-dopant on the microporous PVDF, which is possibly showed a complete coverage to the whole surface of the PVDF to form a smaller pore structure of polyaniline than the pure PVDF.

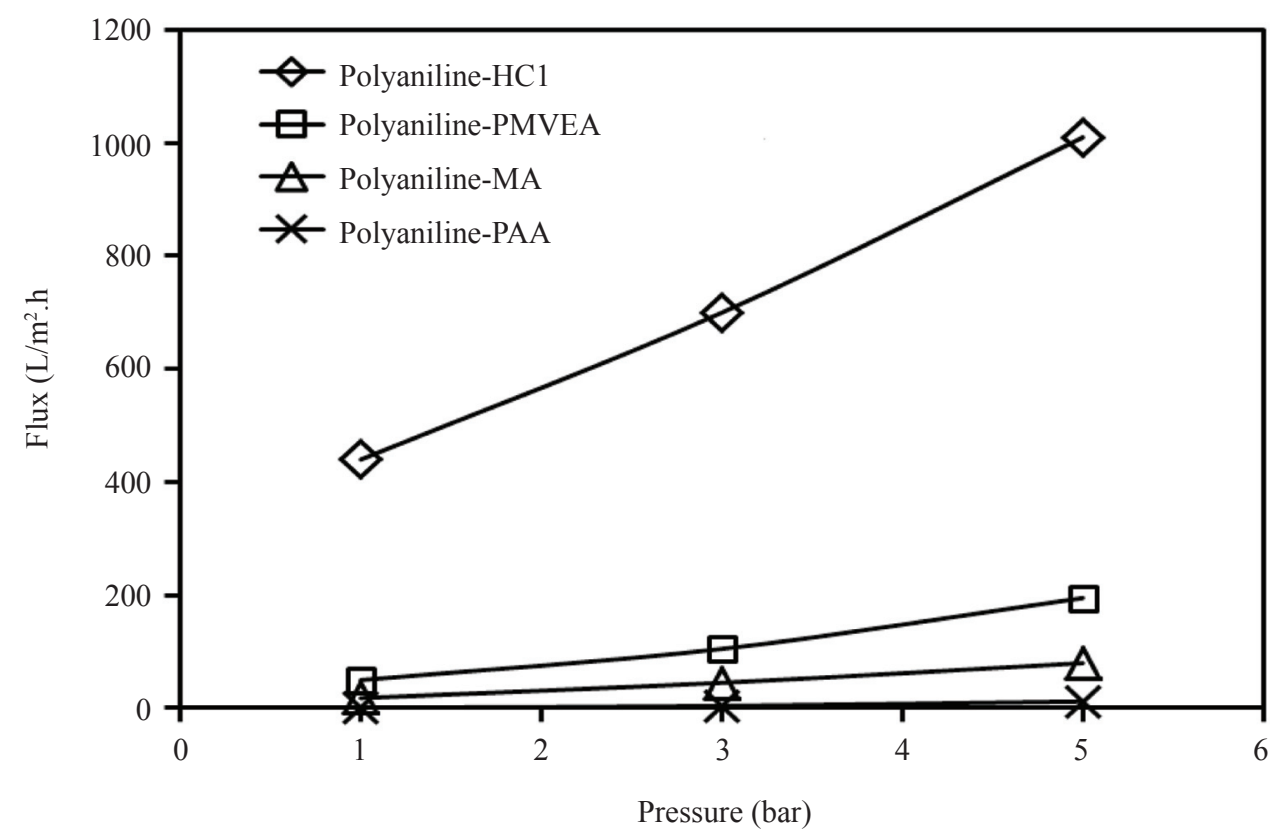

FIGURE 7. Water flux of polyaniline composite membrane with different dopant

Next, the PEGs rejection at different MWs through the membrane in Figure 8 shows that a higher rejection is obtained in the membrane with a lower polyaniline deposition percentage (polyaniline- $\mathrm{HCl}$ and polyanilinePMVEA) compared to the polyaniline-MA and polyaniline-PAA membranes. This result is opposite to the flux value presented in Figure 7. This signifies that the higher polyaniline deposition on the membrane support is not promising in getting a higher rejection of PEG. High rejection is essentially needed to present the ability of the membrane to retain certain molecules and permeate the others, depending on the membrane pore size as well as the shapes, charges and structures of the molecules present. The presence of different acid dopants during polyaniline polymerization has resulted in uneven coating and inconsistent membrane porosity at different membrane area, thus has influenced the rejection value. Zhang et al. reported that the extension of polymerization time has caused the polyaniline-PMVEA to form a micelle structure and elongate on the polymer surface.
It was also found that the rejection was not improved by prolonging the reaction time.

Similar finding was obtained in this study whereby in the initial judgment, the longest polymerization time $(8$ h) was chosen as the best filtration membrane due to the higher polyaniline deposition percentage. Lower rejection is obtained possibly due to incomplete pore coverage on the PVDF micropores. It is also due to pinholes/pores leakage on the membrane happened during membrane compaction stage at above 3 bar prior to PEG filtration. This is supported by the presence of polyaniline traces (blue microparticles) in the permeate stream after the compaction process indicating leaching of polyaniline upon compaction. Polyaniline-PMVEA membrane possessed the highest rejection compared to other membranes, which could reach up to $70 \%$ rejection. SEM micrograph in Figure 6(c) has confirmed that the polyaniline-PMVEA membrane has a better polyaniline coating thus owning higher rejection and reasonable flux. On the other hand, polyaniline- $\mathrm{HCl}$ membrane has the second 
highest rejection. However, this membrane has very high flux which indicating an incomplete continuous polyaniline layer formation on the PVDF that could lead to inconsistent membrane pore sizes. These results showed that complete coating of polyaniline onto PVDF support is vital in obtaining good rejection with reasonable flux like the one observed in polyaniline-PMVEA membrane.

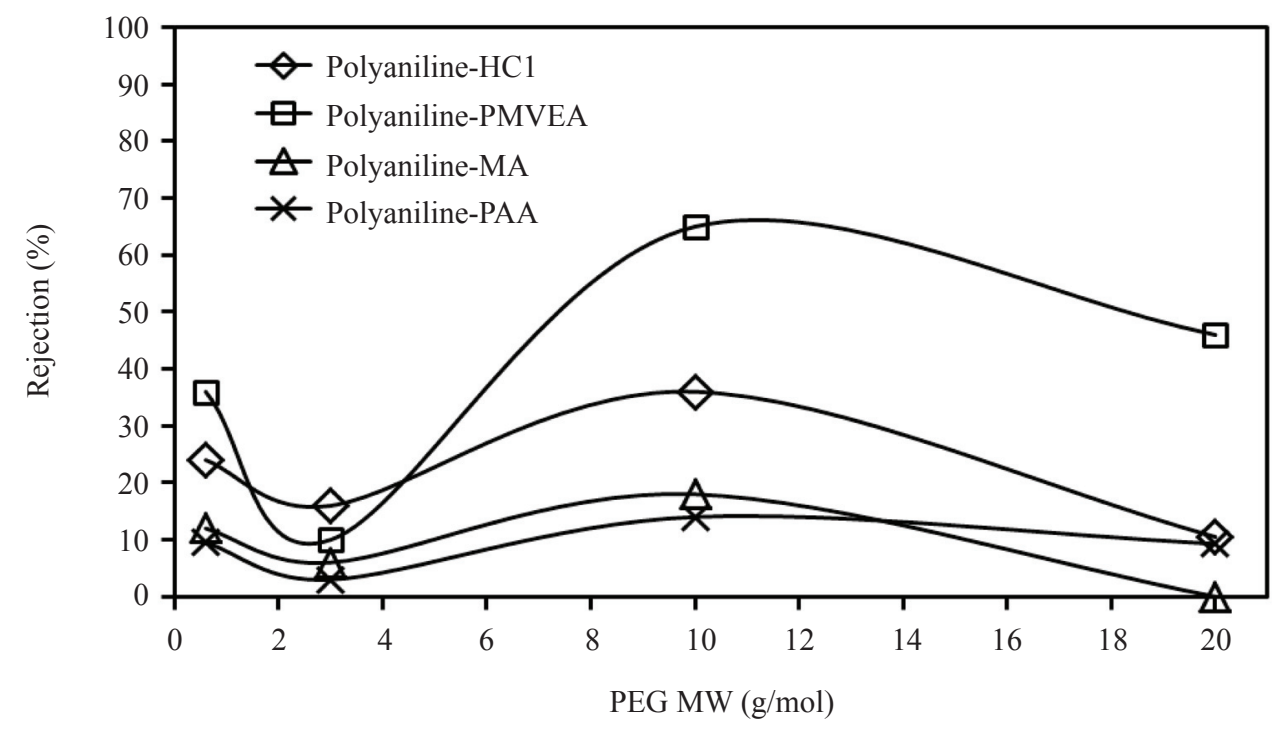

FIGURE 8. PEG rejection of membrane in different molecular weight cut-off of PEG

CONCLUSION

Different acid dopants of HCl, PMVEA, MA and PAA were doped in polyaniline coated onto PVDF microporous support in order to form pressure filtration polyanilinedopant membrane with reasonable flux and rejection filtration properties. This polyaniline-dopant membrane was synthesized by chemical polymerization in a specially fabricated two-compartment cell consisted of the PVDF support clamped between aniline and APS solution at each compartment in order to allow polyaniline polymerization on the support. The deposition amount of polyaniline onto the PVDF support has increased with the increase in polymerization time.The chemical, thermal, electrical and morphological properties of the synthesized polyaniline coated onto PVDF has changed in the presence of PMVEA, MA, $\mathrm{HCl}$ and PAA dopants. FTIR spectra have confirmed the incorporation of various acid into the polyaniline structure. Meanwhile, DSC analysis has confirmed that all fabricated polyaniline membranes are thermally stable based on the consistent melting point with the pure PVDF. The highest conductivity value was obtained in polyaniline-MA membrane while the lowest obtained in polyaniline-PMVEA membranes. However, the best flux and PEG rejection is observed in polyaniline-PMVEA membrane despite its average amount of polyaniline deposition onto the PVDF. Membrane morphology confirmed a complete coating of polyaniline in presence of PMVEA than the other dopants used resulted in a better flux and rejection. Further improvement on the continous polyaniline coating is essential to increase the rejection at the desired value.
ACKNOWLEDGEMENT

The authors gratefully acknowledged the financial support from The Fundamental Research Grant Scheme (FRGS/2/2013/ TK05/UKM/02/4), UKM grant of GUP/2016/086, the Department of Chemical and Process Engineering, UKM for providing conducive research facilities.

REFERENCES

Anderson, M. R., Mattes, B. R., Reiss, H. \& Kaner, R. B. 1991. Gas separation membranes: A novel application for conducting polymers. Synthetic Metals 41(3): 11511154.

Baker, R. W. 2000. Membrane Technology and Applications $3^{\text {rd }}$ Ed.: John Wiley \& Sons, Inc.

Chowdhury, P. \& Saha, B. 2005. Potassium dichromate initiated polymerization of aniline. Indian Journal of Chemical Technology 12: 671-675.

Desilvestro, J. \& Scheifele, W. 1993. Morphology of electrochemically prepared polyaniline. Influence of polymerization parameters. Journal of Materials Chemistry 3(3): 263-272.

Ekarat, D. \& Stephen, T. D. 2009. Interfacial polymerization of water-soluble polyaniline and its assembly using the layer-by-layer technique. Journal of Metals, Materials and Minerals 19: 39-44.

Faneer, K. A., Rohani, R. \& Mohammad, A. W. 2016. polyethersulfone nanofiltration membrane incorporated with silicon dioxide prepared by phase inversion method for xylitol purification. Polymers \& Polymer Composites 24: 803-808. 
Ghani, S. A., Zakaria, A., Shakaff, A. Y. M., Ahmad, M. N. \& Abdullah, A. H. 2012. Enhancing conductive polymer performance using eggshell for ammonia senso. Journal of Physical Science 23(2): 73-83.

Gomes, E. C. \& Oliveira, M. A. S. 2012. Chemical polymerization of aniline in Hydrochloric Acid $(\mathrm{HCl})$ and Formic Acid (HCOOH) media. Differences between the two synthesized polyanilines. American Journal of Polymer Science 2(2): 5-13.

Ibrahim, F., Rohani, R. \& Mohammad, A. W. 2016. Polyaniline multi-coated onto polyvinylidene fluoride and silicon elastomer for pressure filtration membranes. Malaysian Journal of Analytical Science 20(6): 14981509.

Jaleh, B., Gavary, N., Fakhri, P., Muensit, N. \& Taheri, S. M. 2015. Characteristics of PVDF membranes irradiated by electron beam. Membranes (Basel) 5(1): 1-10.

Jelmy, E. J., Ramakrishnan, S., Devanathan, S., Rangaranjan, M. \& Kothurkar, N. K. 2013. Optimization of the conductivity and yield of chemically synthesized polyaniline using a design of experiments. Journal of Applied Polymer Science 130(2): 1047-1057.

Kolla, H. S., Surwade, S. P., Zhang, X., MacDiarmid, A. G. \& Manohar, S. K. 2005. Absolute molecular weight of polyaniline. Journal of the American Chemical Society 127(48): 16770-16771.

Kumar, S., Kumar, S. \& Chakarvarti, S. K. 2004. Non-galvanic synthesis of nanowalled polypyrrole microtubules in ion track membranes. Physics Letters A 327(2): 198-201.

Liao, Y., Farrell, T. P., Guillen, G. R., Li, M., Temple, J. A., Li, X. G. \& Kaner, R. B. 2014. Highly dispersible polypyrrole nanospheres for advanced nanocomposite ultrafiltration membranes. Materials Horizons 1(1): 58-64.

Liao, Y., Yu, D. G., Wang, X., Chain, W., Li, X. G., Hoek, E. M. \& Kaner, R. B. 2013. Carbon nanotube-templated polyaniline nanofibers: synthesis, flash welding and ultrafiltration membranes. Nanoscale 5(9): 3856-3862.

Lu, H., Zhou, Y., Vongehr, S., Hu, K. \& Meng, X. 2011. Electropolymerization of PANI coating in nitric acid for corrosion protection of 430 SS. Synthetic Metals 161(13): 1368-1376.

Lv, P., Zhao, Y., Liu, F., Li, G., Dai, X., Ji, X., Dong, Z. \& Qiu, X. 2016. Fabrication of polyaniline/polyimide composite fibers with electrically conductive properties. Applied Surface Science 367: 335-341.

Malmonge, L. F., Langiano, S. D. C., Cordeiro, J. M. M., Mattoso, L. H. C. \& Malmonge, J. A. 2010. Thermal and mechanical properties of PVDF/PANI blends. Materials Research 13(4): 465-470.

Mansouri, J., Harrisson, S. \& Chen, V. 2010. Strategies for controlling biofouling in membrane filtration systems: challenges and opportunities. Journal of Materials Chemistry 20(22): 4567-4586.

McVerry, B. T., Temple, J. A., Huang, X., Marsh, K. L., Hoek, E. M. \& Kaner, R. B. 2013. Fabrication of lowfouling ultrafiltration membranes using a hydrophilic, self-doping polyaniline additive. Chemistry of Materials 25(18): 3597-3602.

Pignatello, J. J., Oliveros, E. \& MacKay, A. 2006. Advanced oxidation processes for organic contaminant destruction based on the Fenton reaction and related chemistry. Critical reviews in environmental science and technology 36(1): 1-84.

Plesu, N., Ilia, G., Bandur, G. \& Popa, S. 2005. Chemical polymerization of aniline in phenylphosphinic acid. Journal of the Serbian Chemical Society 70(10): 11691182.

Pournaghi-Azar, M. H. \& Habibi, B. 2007. Electropolymerization of aniline in acid media on the bare and chemically pre-treated aluminum electrodes: A comparative characterization of the polyaniline deposited electrodes. Electrochimica Acta 52(12): 4222-4230.

Qaiser, A. A., Hyland, M. M. \& Patterson, D. A. 2011. Membrane potential and impedance studies of polyaniline composite membranes: Effects of membrane morphology. Journal of Membrane Science 385-386: 67-75.

Richard, B., Nigel, J. C. \& Sarah, H. C. 2014. Conductive polymers: Towards a smart biomaterial for tissue engineering. Acta Biomaterialia 10: 2341-2353.

Rohani, R., Hyland, M. \& Patterson, D. 2011. A refined one-filtration method for aqueous based nanofiltration and ultrafiltration membrane molecular weight cut-off determination using polyethylene glycols. Journal of Membrane Science 382(1-2): 278-290.

Rohani, R., Hyland, M. \& Patterson, D. A. 2016. Effects of process parameters on polyaniline nanofiltration membranes synthesis via phase inversion-immersion precipitation method. Journal of Engineering Science and Technology 11: 16-35.

Sairam, M., Nataraj, S. K., Aminabhavi, T. M., Roy, S. \& Madhusoodana, C. D. 2006. Polyaniline membranes for separation and purification of gases, liquids, and electrolyte solutions. Separation \& Purification Reviews 35(4): 249-283.

Sapurina, I. Y. \& Stejskal, J. 2012. Oxidation of aniline with strong and weak oxidants. Russian Journal of General Chemistry 82(2): 256-275.

Stassen, I., Sloboda, T. \& Hambitzer, G. 1995. Membrane with controllable permeability for drugs. Synthetic Metals 7(1): 249-283.

Thanpitcha, T., Sirivat, A., Jamieson, A. M. \& Rujiravanit, R. 2008. Synthesis of polyaniline nanofibrils using an in situ seeding technique. Synthetic Metals 158(17-18): 695-703.

Wu, Y.-J., Ho, K.-S., Cheng, Y.-W., Chao, L., Wang, Y.-Z., Hsieh, T.-H., Ho, T.-H. \& Han, Y.-K. 2013. Studies on the synthesis of low molecular weight, one-dimensional polyanilines prepared by fast emulsion polymerization using (n-dodecylbenzenesulfonic acid)/ $\mathrm{HCl}$ emulsifiers Polymer International 62(4): 581-590.

Xu, H., Li, X. \& Wang, G. 2015. Polyaniline nanofibers with a high specific surface area and an improved pore structure for supercapacitors. Journal of Power Sources 294: 16-21. 
Yusoff, I. I., Rohani, R. \& Mohammad, A. W. 2016. Investigation of the formation characteristics of polyaniline and its application in forming free-standing pressure filtration membranes. Journal of Polymer Research 23(177): 1-13.

Yusoff, I. I., Rohani, R. \& Mohammad, A. W. 2016. Pressure driven conducting polymer membranes derived from layer by layer formation and characterization: A review. Journal of Engineering Science and Technology 11(8): 1183-1206.

Yusoff, I. I., Rohani, R. \& Mohammad, A. W. 2017. Molecular weight cut-off determination of pressure filtration membranes via colorimetric detection method. Malaysian Journal of Analytical Sciences 21: 484-495.

Zhang, L., Peng, H., Sui, J., Kilmartin, P. A. \& Travas-Sejdic, J. 2008. Polyaniline nanotubes doped with polymeric acids. Current Applied Physics 8(3-4): 312-315.

Zhang, X., Zhu, J., Haldolaarachchige, N., Ryu, J., Young, D. P., Wei, S. \& Guo, Z. 2012. Synthetic process engineered polyaniline nanostructures with tunable morphology and physical properties. Polymer International 53(10): 2109-2120.

\section{*Rosiah Rohani}

Izzati Izni Yusoff

Farah Adlyna Mey Efdi

Mohd Usman Mohd Junaidi

Department of Chemical and Process Engineering

Faculty of Engineering and Built Environment

Universiti Kebangsaan Malaysia

43600 UKM Bangi, Selangor, Malaysia.

\section{Asif Ali Qaiser}

Department of Polymer \& Process Engineering

Director Student Affairs

University of Engineering \& Technology (UET) Lahore

Pakistan.

*Corresponding author; email: rosiah@ukm.edu.my

Received Date: $1^{\text {st }}$ August 2017

Accepted Date: $28^{\text {th }}$ November 2017

In Press date: $15^{\text {th }}$ December 2017

Published date: $31^{\text {st }}$ December 2017 